1 Dry deposition of reactive nitrogen to European ecosystems: a comparison of inferential models across the

3 NitroEurope network - Supplementary Material

4

5

\author{
C. R. Flechard, E. Nemitz, R. I. Smith, D. Fowler, A. T. Vermeulen, A. Bleeker,
} J.W. Erisman, D. Simpson, L. Zhang, Y. S. Tang and M. A. Sutton

\title{
A1 Introduction
}

This supplement provides additional details concerning the implementation of four dry deposition (inferential) routines as part of the model inter-comparison at the ecosystem scale presented in the aforementioned article, with respect to ecosystem characteristics, micrometeorology and canopy wetness simulation.

\section{A2 Canopy characteristics}

For the modelling of trace gas and particle deposition at national or regional scales, the inferential routines of the four models (i.e. CBED, CDRY, EMEP-03, IDEM) normally use either land use class (LUC)-specific, monthly default values, or phenological functions, for the key canopy characteristics (canopy height $h_{\mathrm{c}}$, roughness length $z_{0}$ and leaf area index LAI), since such data are not available at the ecosystem scale for every node of the grid domain nor for every day of the year. These default values or functions for each LUC logically differ between the four models since they were developed for different countries or climatic zones.

In this paper, however, the models are applied locally to a number of ecosystem study sites, rather than to a whole geographical domain. Measurements of $h_{\mathrm{c}}$ and of LAI were made as part of CarboEurope IP at most sites of the NitroEurope (NEU) inferential network (Table 1 of main paper). These measurements were carried out typically a few times during the growing season but the data capture was very uneven between sites. While the temporal (seasonal) variations were extremely well documented with very frequent (weekly) measurements at a few sites of the network, too few data were available at the majority of the 
other sites to reliably interpolate over time, as required for input to deposition models. This is largely due to the fact that in many cases only the maximum LAI was recorded during the growing season, while the conditions at the start and end of the growing season can only be guessed. With several cuts per year in grasslands, or more than one crop per year in arable systems, the frequent measurements needed were not available for all sites. There was also the added problem that the NEU project (2006-2010) was shifted in time relative to CarboEurope IP (2004-2008), so that much of the LAI and $h_{\mathrm{c}}$ data collected as part of CarboEurope were not contemporaneous with the NEU trace gas and aerosol datasets (initiated in 2007). Another difficulty resides in the method or type of LAI measurement (single-sided, double-sided, projected, total) not being recorded, so that the available data may not be compatible with the input required for modelling.

Based on these considerations, model base runs in this study use model default values of LAI, combined with time-interpolated values of $h_{\mathrm{c}}$ derived from the available measured data ('ModLAI / MeasHc', see Table A2). The choice of model default LAI is primarily motivated by the potentially large error in measured LAI data, which may be considered just as uncertain as model default values. By contrast, $h_{\mathrm{c}}$ is a more easily measured and defined canopy characteristic, which can arguably be considered constant for forests over the time frame of CarboEurope and NEU. More importantly, the measurement heights for the sonic anemometers and for the DELTA gas and aerosol sampling apparatus were in practice set according to the true $h_{\mathrm{c}}$. Thus the measured pollutant concentrations reflected vertical gradients and turbulent mixing conditions consistent with the real $h_{\mathrm{c}}$, but not necessarily with a model default value.

Nevertheless, if the objective is to fully inter-compare models, rather than obtain the 'truest' model deposition estimates, one could argue that $h_{\mathrm{c}}$ and LAI descriptions in default lookup tables can be regarded as intrinsic model parameters, and should therefore both be used as inputs ('ModLAI / ModHc'). Conversely, using both sets of measured LAI and $h_{\mathrm{c}}$ as common inputs to the four models ('MeasLAI / MeasHc') could be defended as providing a better setup for inter-comparing the models treatment of surface resistances, in which the confounding effects of surface roughness and area are removed. These alternative choices for the model inputs values of LAI and $h_{\mathrm{c}}$ are presented to assess the sensitivity of annual dry deposition fluxes (Figure A3). For the reconstruction of seasonal time series of daily $h_{\mathrm{c}}$ and LAI, the data were interpolated between consecutive measurements if their time resolution was sufficient; 
1 alternatively, generic annual curves were computed on the basis of the standard EMEP-03

2 phenological functions (Simpson et al., 2003), then scaled using the measured minimum and

3 maximum values at each site.

\section{A3 Micrometeorological data}

6 Fundamental variables needed to compute the atmospheric resistances $R_{\mathrm{a}}$ and $R_{\mathrm{b}}$ include $u *$, sensible heat flux $H$, and $z_{0}$. At 51 of the 55 sites of the NEU inferential network, long-term eddy covariance (EC) measurements of $\mathrm{CO}_{2}$ and $\mathrm{H}_{2} \mathrm{O}$ exchange were carried out within the framework of CarboEurope IP (Aubinet et al., 2000), and thus actual in-situ measurements of $u *$ and $H$ were available on a half-hourly basis and obtained courtesy of the CarboEurope-IP database. For the 4 remaining non-CarboEurope IP sites (DE-Hoe, FI-Lom, NL-Spe, UA-Pet), eddy covariance flux measurements were initiated as part of NitroEurope IP. In the base model runs presented hereafter, all available measured (EC) $u *$ and $H$ data were used by default for the calculation of atmospheric resistances.

For cases when valid turbulence data from EC were not available due to instrument failure, strong nocturnal atmospheric stability, small wind speeds or insufficient fetch (Aubinet et al., 2000), $u *$ and $H$ needed to be gap-filled from standard meteorological data (wind speed, net radiation, temperature) measured at each site. This was done in a similar fashion to meteorological sub-modules of regional chemical transport models (CTMs), which derive their $u_{*}$ from numerical weather prediction (NWP) model output data, such that (Thom, 1975):

$u_{*}=\frac{\kappa U\left(z_{r e f}-d\right)}{\left[\ln \left(\frac{z_{r e f}-d}{z_{0}}\right)-\psi_{\mathrm{M}}\left(\frac{z_{r e f}-d}{L}\right)+\psi_{\mathrm{M}}\left(\frac{z_{0}}{L}\right)\right]}$

where $z_{0}$ is roughness length and $d$ is displacement height, both being dependent on $h_{\mathrm{c}}, U$ is wind speed, $\kappa$ is von Karman's constant $(=0.41), \psi_{\mathrm{M}}$ is the integrated atmospheric stability correction function for momentum, and $L$ is the Obukhov stability length:

$$
L=-\frac{\rho_{a} \theta C_{p} u_{*}^{3}}{\kappa g H}
$$


1 with $\rho_{\mathrm{a}}$ the density of dry air $\left(\mathrm{g} \mathrm{m}^{-3}\right), \theta$ the potential air temperature $(\mathrm{K}), C_{\mathrm{p}}$ the specific heat 2 capacity of air $\left(=1.005 \mathrm{~J} \mathrm{~g}^{-1} \mathrm{~K}^{-1}\right)$ and $g$ the gravitational acceleration $\left(=9.81 \mathrm{~m} \mathrm{~s}^{-2}\right.$ ) (Thom, 3 1975). However, this also requires the knowledge of $L$, which is itself a function of both $u *$ and $H$ (Eq. A2). In the absence of valid micrometeorological measurements, a first and necessary step adopted here as in other models (e.g. Bassin et al., 2004) consists in a rough estimation of $H$ assuming the closure of the surface energy balance and a partitioning of the available energy such that:

$H=R_{\mathrm{n}}-\lambda E-G$

Here $G$ is the ground heat flux, and the latent heat flux $\lambda E$ was estimated using the PenmanMonteith (P-M) equation, which may only be done in a first approximation assuming neutral stratification, since $H$ and $L$ are both unknown. As $R_{\mathrm{a}}$ and $R_{\mathrm{s}}$ are also needed, as rather poorly quantified drivers of evaporation, in the P-M equation, both estimates of $\lambda E$ and $H$ are necessarily quite uncertain, all the more as the surface energy closure assumption is often not confirmed in the field (e.g. Wohlfahrt et al., 2009). From the $H$ estimate thus obtained, both $u$ * and $L$ are then calculated iteratively using Eqs. (A1) and (A2). The overall effect of the gapfilling procedure for $H$ on annual $\mathrm{N}_{\mathrm{r}}$ fluxes appears to be small, however, as the error in $H$ does not propagate very strongly into $u_{*}$ (Bassin et al., 2004), and also because micrometeorological data gaps are by nature strongly correlated with periods of reduced wind speeds and suppressed turbulence, during which potential rates of tracer exchange are very small.

\section{A4 Surface potentials}

For the calculation of stomatal and non-stomatal resistances, and of the $\mathrm{NH}_{3}$ compensation point (Eqs. 3 to 10 in main Paper), values of the surface scalars temperature and relative humidity are required. From the viewpoint of a numerical weather prediction (NWP) model, 'surface' actually means anything between the measurement height $\left(\mathrm{z}_{\mathrm{ref}}\right)$ of a standard meteorological station within the surface layer, typically 2-3 m above ground or up to 10 meters above tree tops in the case of a forest, up to 50-100 m. From a micrometeorological, field-scale point of view, 'surface' corresponds to the notional height $z_{\mathrm{s}}=d+z_{0}$ ', 'below' the viscous sublayer, with $z_{0}$ ' the roughness length for heat and trace gases (Monteith and Unsworth, 1990). There can be substantial differences between scalars at $z_{\mathrm{s}}$ and $z_{\text {ref, }}$ 
1 depending on the intensity of turbulent mixing, canopy roughness, solar radiation and

2 atmospheric thermal stratification, especially over short vegetation. The temperature

3 difference between $z_{\mathrm{s}}$ and $z_{\text {ref }}$ has a particularly strong impact on the calculation of the

4 stomatal compensation point $\left(\chi_{s}\right)$, which increases exponentially with temperature and doubles

5 approximately with every additional $4-5 \mathrm{~K}$ (Flechard and Fowler, 2008; Personne et al.,

6 2009), while for stomatal resistance the $v p d$ stress factor $f_{\mathrm{e}}$ is best evaluated using relative

7 humidity at $z_{\mathrm{s}}$.

8 By default in this paper, model base runs used ambient temperature and relative humidity data 9 as measured by meteorological stations at $z_{\text {ref }}$, a few $\mathrm{m}$ above vegetation, which is the closest approximation to the outputs of NWP models that are normally used as inputs to CTMs. The sensitivity of modelled fluxes to input $T$ and $R H$ was however tested in alternative model runs by using the potentials at $z_{\mathrm{s}}$ rather than $z_{\text {ref }}$ as input to the deposition routines (see 'Surface potentials' model runs in Table A2 and Fig. A3). The $z_{\mathrm{s}}$ potentials were first computed from measured micrometeorological fluxes of both sensible $(H)$ and latent heat $(\lambda E)$, following (e.g. Monteith and Unsworth, 1990):

$T\left(z_{0}^{\prime}\right)=T\left(z_{r e f}-d\right)+\frac{H}{\rho \mathrm{C}_{\mathrm{p}}}\left(R_{\mathrm{a}}\left(z_{r e f}-d\right)+R_{\mathrm{b}, \text { heat }}\right)$

and

$e\left(z_{0}^{\prime}\right)=e\left(z_{r e f}-d\right)+\frac{p E}{\rho \varepsilon}\left(R_{\mathrm{a}}\left(z_{r e f}-d\right)+R_{\mathrm{b}, \mathrm{H}_{2} \mathrm{O}}\right)$

where $e$ is water vapour pressure, $p$ is atmospheric pressure, $E$ is the water vapour flux and $\varepsilon$ is the ratio of the molecular weight of water to the mean molecular weight of dry air (= 18/29), and the surface relative humidity is given by

$$
R H\left(z_{0}{ }^{\prime}\right)=\frac{e\left(z_{0}{ }^{\prime}\right)}{e_{\text {sat }}\left(T\left(z_{0}{ }^{\prime}\right)\right)}
$$

where $e_{\text {sat }}(T)$ is the saturation water vapour pressure at $T$.

\section{A5 Canopy wetness}

Surface wetness controls non-stomatal resistances for soluble trace gases in all four models, particle rebound (EMEP-03, CDRY), and even stomatal 'blocking' (CDRY). Depending on 
1 the process, chemical species and model considered, the wetness effect is either quantified by

2 a continuous function of $R H$ (e.g. Eq. 4-7 in main paper), or qualified by a binary (or boolean)

3 indicator (wet $=1$ or true, dry $=0$ or false), with different surface resistances for the dry and

4 wet cases. In the IDEM model, both a wetness indicator and the $R H$ function (Eq. (7) in main paper) are used in turns for $R_{\text {ext }}$ in the case of $\mathrm{NH}_{3}$. Canopy wetness was actually monitored at a few sites of the NEU network (e.g. BE-Bra, CH-Oe1, NL-Spe, FR-Gri, UK-Amo) using surrogate sensors (e.g. Model 237 Leaf Wetness Sensor, Campbell Scientific, Logan, UT), but at most sites no measurements were available. For models in which a wetness boolean was required, this needed to be estimated from ancillary environmental data.

Although modelled $R_{\mathrm{w}}, R_{\mathrm{c}}$ and deposition flux are highly sensitive to wetness, canopy wetness is difficult to predict reliably. This is compounded by the fact that, although a leaf surface may appear dry to the eye or to surrogate wetness sensors, thin water films on microscopic scales, as demonstrated by leaf wetness/conductivity clips (Burkhardt and Eiden, 1994), still provide sinks for atmospheric gases, and thus a leaf surface might seldom be fully 'dry'. Various $R H$ thresholds have been used as proxies to determine canopy wetness; van Jaarsveld (2004) determines a dry-wet switch point of $87 \%$ from surface wetness observations over mixed forest, while for grassland Wichink Kruit et al. (2008, 2010) suggest a smaller threshold at $71 \%$. Both studies used ambient ( $\left.\mathrm{z}_{\mathrm{ref}}\right) \mathrm{RH}$ data, but it could be that the same analyses using $R H\left(d+z_{0}{ }^{\prime}\right)$ (see Section A4) might have yielded thresholds which were more similar to each other, given the larger vertical $R H$ gradients over grassland than over forest. Some dry deposition models such as CDRY predict surface wetness semi-mechanistically and distinguish dew from rain, based on precipitation data and on night-time cloud cover and $u *$ for dew formation. Other models either treat wetness as an input variable provided e.g. by NWP models, or use rule-of-thumb decisions based on ambient $R H$ and precipitation. The CBED model does not actually require any wetness indicator to quantify the non-stomatal resistance for $\mathrm{N}_{\mathrm{r}}$ gases.

Since the treatment of surface wetness prediction by the inferential models is rather crude and model-dependent, and since surface wetness can be regarded as an input variable to the models (rather than an output), it was preferred here to use a common wetness parameterisation to feed all four models. This suppresses the inter-model variability that would caused by differing wetness schemes, and allows the model intercomparison to focus on discrepancies in surface resistances and fluxes. The approach used to simulate common 
wetness data was based on the mechanistic, big leaf, surface wetness energy balance (SWEB) and canopy water budget model by Magarey et al. (2006). The SWEB model was originally designed for grapes but model canopy characteristics (LAI, $h_{\mathrm{c}}$ ) can be adjusted to deal with other crops and vegetation types. Inputs to the model are $T$ and $R H$ at the canopy height, precipitation, wind speed $U$ measured at $\mathrm{z}_{\mathrm{ref}}-d$ above the canopy and $R_{\mathrm{n}}$. The model is dynamic, allowing surface water to accumulate up to the maximum storage capacity and to evaporate depending on meteorological conditions. The model therefore requires continuous input data, which were routinely available from meteorological stations at each site of the network. For cases when key meteorological variables were missing to run SWEB, but ambient $R H$ was still available, canopy wetness was decided on the basis of a wet-dry threshold of $81 \%$, which corresponds to the deliquescence point of ammonium sulphate (Flechard et al., 1999), although in reality deposited material on leaf surfaces is a mixture of various salts and organic aerosols. For the CDRY model, which requires a distinction of dewfrom rain-wetted surfaces, the output of SWEB was split following CDRY decision rules.

The SWEB scheme (Magarey et al., 2006) was run systematically, regardless of the inferential model used, but the wetness output was slightly model-dependent, due to the differences in model LAI defaults. SWEB outputs are evaluated and compared in Fig. A2 with measured data at five sites of the network, which were equipped with surrogate leaf wetness sensors (BE-Bra, CH-Oe1, FR-Gri, NL-Spe and UK-Amo). The data show the frequency (or probability) of wetness occurrence as a function of the time of day; there are strong seasonal variations that are driven by meteorological conditions, but for clarity the data are here averaged over the whole year. All sites describe a strong diurnal cycle, with the largest wetness frequency occurring toward late night/early morning, and the driest period occurring in mid to late afternoon, consistent with night-time dewfall and daytime evaporation of foliar wetness. The occurrence of rainfall may be considered to be randomly distributed through the day, having thus no effect on the shape of the diurnal cycle, though this is probably not be true for all sites.

Diurnal patterns and overall average wetness frequency are broadly consistent between observations and modelled values. The "wettest" canopy was found at the cut grassland site CH-Oe1 in both measurements and model simulations, with a night-time frequency of $90 \%$ and a daytime minimum of $40 \%$. By contrast the other sites showed a night-time wetness probability of $50-80 \%$ and daytime minima of typically $20-30 \%$. This was consistent with the 
average annual rainfall being largest at CH-Oe1 (1200 mm). CH-Oe1 and FR-Gri had frequent dewfall due to frequent night-time inversions in semi-continental climates, while BEBra, NL-Spe and UK-AMo are windier sites in more oceanic conditions.

Differences between the various SWEB model runs at each site shown in Fig. A2 can essentially be ascribed to the canopy-scale, leaf surface wetness storage capacity, and consequently the different average leaf wetness durations, which are driven by different LAI defaults from each model. For example at the arable site of FR-Gri, the model run using EMEP-03 LAI defaults provided much smaller wetness frequencies than the other models, which was consistent with a much smaller mean annual LAI in EMEP-03 (0.42) than in CBED (1.35), CDRY (1.22) and IDEM (1.72). SWEB was also run for comparison using estimates of LAI provided at each site. At BE-Bra, CH-Oe1 and FR-Gri this did not significantly improve nor lessen SWEB performance, as compared with observations, but at NL-Spe and UK-AMo there was a noticeable improvement for night-time conditions, where observations apparently indicated much less frequent wetness occurrences than the canopy water budget approach.

It should be noted that "observed" wetness measurements can have significant uncertainties, and for example the small wetness values seen at night-time at the blanket bog site UK-AMo seem somewhat surprising (one would expect almost 100\% humidity near the surface at night at such sites, which ought to cause wetness), but the representativity of, and the potential errors in, wetness measurements made using generally only one surrogate sensor cannot be assessed here and have been treated elsewhere (e.g. Wichink Kruit et al., 2008). The lack of spatial or vertical resolution in such data and the different behaviours of wetness sensors and leaves or needles with respect to water evaporation, condensation and to particle deposition, which favours condensation at smaller $R H$ (Burkhardt and Eiden, 1994), might explain some of the discrepancies oberved between measurements and models. On the other hand, any surface wetness and energy balance approach will suffer shortcomings and may perform better for certain types of vegetation than others. It is perhaps not surprising that the SWEB model by Magarey et al. (2006), having been developed for agricultural vegetation, seemed to give best results over grass at $\mathrm{CH}-\mathrm{Oe} 1$ and cropland at FR-Gri, but in forests (BE-Bra, NLSpe in Fig. A2) big leaf limitations may be significant. More validation data are required, but based on the few sites where a comparison was performed (Fig. A2), the SWEB approach may be considered robust and valid for the purposes of inferential modelling. 
3 Aubinet, M., Grelle, A., Ibrom, A., Rannik, U., Moncrieff, J., Foken, T., Kowalski, A.S., 4 Martin, P.H., Berbigier, P., Bernhofer, Ch., Clement, R., Elbers, J., Granier, A., Grünwald, T., 5 Morgenstern, K., Pilegaard, K., Rebmann, C., Snijders,W., Valentini, R. and Vesala, T.: 6 Estimates of the annual net carbon and water exchange of forests: the EUROFLUX methodology, Adv. Ecol. Res., 30, 113-171, 2000.

8 Bassin, S., Calanca, P., Weidinger, T., Gerosa, G. and Fuhrer, J.: Modelling seasonal ozone fluxes to grassland and wheat: model improvement, testing, and application, Atmos. Environ., 38, 2349-2359, 2004.

Burkhardt, J. and Eiden, R.: Thin water films on coniferous needles, Atmos. Environ., 28, 2001-2011, 1994.

Flechard, C.R., Fowler, D., Sutton, M.A., and Cape, J.N.: A dynamic chemical model of bidirectional ammonia exchange between semi-natural vegetation and the atmosphere, Q. J. Roy. Meteor. Soc., 125, 2611-2641, 1999.

Flechard, C.R. and Fowler, D.: Effects of Changing Temperature on Leaf Surface Water-Film Chemistry and Trace Gas Exchange Processes over Terrestrial Vegetation, in: The Impact of Climate Change on Air Quality, The 4th ACCENT Barnsdale Expert Workshop, Editors: P. Builtjes, D. Fowler, J. Feichter, A. Lewis, P. Monks and P. Borrell, ACCENT Secretariat, Urbino, 155-161, 2008.

21 Magarey, R.D., Russo, J.M. and Seem, R.C.: Simulation of surface wetness with a water budget and energy balance approach, Agr. Forest Meteorol., 139, 373-381, 2006.

Monteith, J.L. and Unsworth, M.H.: Principles of Environmental Physics, 2nd edition. Edward Arnold, London. 291 pp, 1990.

Personne, E., Loubet, B., Herrmann, B., Mattsson, M., Schjoerring, J.K., Nemitz, E., Sutton, M.A. and Cellier, P.: SURFATM-NH3 : a model combining the surface energy balance and bi-directional exchanges of ammonia applied at the field scale, Biogeosciences, 6, 13711388, 2009.

Simpson, D., Fagerli, H., Jonson, J.E., Tsyro, S., Wind, P. and Tuovinen, J.-P.: 
1 Unified EMEP Model Description, EMEP Status Report 2003, ISSN 0806-4520, Det

2 Meteorologisk Institutt, Oslo, 2003.

3 Thom, A.S.: Momentum, mass and heat exchange of plant communities. In: Vegetation and

4 the atmosphere, vol. 1 (Ed: J.L. Monteith), pp 57-109. Academic Press, London, 1975.

5 van Jaarsveld J.A.: The Operational Priority Substances model: Description and validation of

6 OPS-Pro 4.1, RIVM report 500045001/2004, 156 pp., Bilthoven, The Netherlands, 2004.

7 Wichink Kruit, R.J., Jacobs, A.F.G. and Holtslag, A.A.M.: Measurements and estimates of

8 leaf wetness over agricultural grassland for dry deposition modelling of trace gases, Atmos.

9 Environ., 42, 5304-5316, 2008.

10 Wichink Kruit, R.J., van Pul, W.A.J., Sauter, F.J., van den Broek, M., Nemitz, E., Sutton, 11 M.A., Krol, M. and Holtslag, A.A.M.: Modelling the surface-atmosphere exchange of 12 ammonia, Atmos. Environ., 44 (7), 945-957, 2010.

13 Wohlfahrt, G., Haslwanter, A., Hörtnagl, L., Jasoni, R.L., Fenstermaker, L.F., Arnone, J.A. 14 and Hammerle, A.: On the consequences of the energy imbalance for calculating surface 15 conductance to water vapour, Agr. Forest Meteor., 149, 1556-1559, 2009. 
1 Table A1. Selected references for the measurement sites

\begin{tabular}{|c|c|c|c|c|c|c|}
\hline Site Code & Site Name & Authors & Year & Journal & Vol. & Pages \\
\hline BE-Bra & Brasschaat & Neirynck et al. & 2005 & Atmos. Environ. & 39 & $5013-5024$ \\
\hline BE-Vie & Vielsalm & Heinesch et al. & 2007 & Boundary Layer Meteorol. & 122 & $457-478$ \\
\hline CH-Lae & Laegeren & Ruehr et al. & 2010 & Biogeochemistry & 98 & $153-170$ \\
\hline CZ-BK1 & Bily Kriz & Sedlak et al. & 2010 & Agric. Forest Meteorol. & 150 & $736-744$ \\
\hline DE-Hai & Hainich & Knohl et al. & 2003 & Agric. Forest Meteorol. & 118 & $151-167$ \\
\hline DE-Hoe & Höglwald & Kreutzer et al. & 2009 & Plant Biol. & 11 & $643-649$ \\
\hline DE-Tha & Tharandt & Grünwald and Bernhofer & 2007 & Tellus & $59 B$ & $387-396$ \\
\hline DE-Wet & Wetzstein & Anthoni et al. & 2004 & Glob. Change Biol. & 10 & 2005-2019 \\
\hline DK-Sor & Soroe & Pilegaard et al. & 2003 & Boreal Environ. Res. & 8 & $315-333$ \\
\hline ES-ES1 & El Saler & Sanz et al. & 2002 & Environm. Pollution & 118 & $259-272$ \\
\hline ES-LMa & Las Majadas & Casals et al. & 2009 & Soil Biol. Biochem. & 41 & $1915-1922$ \\
\hline FI-Hyy & Hyytiälä & Vesala et al. & 2005 & Glob. Biogeochem. Cycles & 19 & $\mathrm{n}^{\circ} \mathrm{GB} 2001$ \\
\hline FI-Sod & Sodankylä & Thum et al. & 2008 & Biogeosciences & 5 & $1625-1639$ \\
\hline FR-Fon & Fontainbleau & Davi et al. & 2006 & Agric. Forest Meteorol. & 139 & $269-287$ \\
\hline FR-Hes & Hesse & Granier et al. & 2008 & Ann. For. Sci. & 64 & $n^{\circ} 704$ \\
\hline FR-LBr & Le Bray & Rivalland et al. & 2005 & Ann. Geophysicae & 23 & 291-304 \\
\hline FR-Pue & Puechabon & Allard et al. & 2008 & Glob. Change Biol. & 14 & $714-725$ \\
\hline IT-Col & Collelongo & Scartazza et al. & 2004 & Oecologia & 140 & $340-351$ \\
\hline IT-Ren & Renon & Marcolla et al. & 2005 & Agric. Forest Meteorol. & 130 & $193-206$ \\
\hline IT-Ro2 & Roccarespampani & Tedeschi et al. & 2006 & Glob. Change Biol. & 12 & $110-121$ \\
\hline IT-SRo & San Rossore & Chiesi et al. & 2005 & Agric. Forest Meteorol. & 135 & $22-34$ \\
\hline NL-Loo & Loobos & Dolman et al. & 2002 & Agric. Forest Meteorol. & 111 & $157-170$ \\
\hline NL-Spe & Speulderbos & Erisman et al. & 1999 & Water, Air, and Soil Pollution & 109 & $237-262$ \\
\hline PT-Esp & Espirra & Pereira et al. & 2007 & Biogeosciences & 4 & $791-802$ \\
\hline PT-Mi1 & Mitra II (Evora) & Pereira et al. & 2007 & Biogeosciences & 4 & $791-802$ \\
\hline RU-Fyo & Fyodorovskoye & Ramonet et al. & 2002 & Tellus & $54 \mathrm{~B}$ & $713-734$ \\
\hline SE-Nor & Norunda & Grelle et al. & 1999 & Agric. Forest Meteorol. & $98-99$ & $563-578$ \\
\hline SE-Sk2 & Skyttorp & Lindroth et al. & 2008 & Tellus & $60 \mathrm{~B}$ & $129-142$ \\
\hline UK-Gri & Griffin & Clement et al. & 2003 & Scottish Forestry & 57 & $5-10$ \\
\hline DE-Meh & Mehrstedt & Don et al. & 2009 & Glob. Change Biol. & 15 & $1990-2002$ \\
\hline ES-VDA & Vall d'Alinyà & Sebastià & 2007 & J. App. Ecology & 44 & $158-167$ \\
\hline FI-Lom & Lompolojänkkä & Aurela et al. & 2009 & Boreal Environ. Res. & 14 & $699-710$ \\
\hline HU-Bug & Bugac & Nagy et al. & 2007 & Agric. Ecosys. Environ. & 121 & $21-29$ \\
\hline IT-Amp & Amplero & Gavrichkova et al. & 2010 & Agric. Ecosys. Environ. & 136 & $87-96$ \\
\hline IT-MBo & Monte Bondone & Vescovo and Gianelle & 2006 & Agric. Ecosys. Environ. & 115 & $141-149$ \\
\hline NL-Hor & Horstermeer & Hendriks et al. & 2007 & Biogeosciences & 4 & $411-424$ \\
\hline PL-wet & POLWET & & & & & \\
\hline UK-AMo & Auchencorth Moss & Flechard et al. & 1998 & Quart. J. Roy. Meteorol. Soc. & 124 & $733-757$ \\
\hline CH-Oe1 & Oensingen & Flechard et al. & 2005 & Glob. Change Biol. & 11 & $2114-2127$ \\
\hline DE-Gri & Grillenburg & Tittebrand et al. & 2009 & Theor. Appl. Climatol. & 98 & $171-186$ \\
\hline DK-Lva & Rimi & Gryning et al. & 2009 & Boreal Environ. Res. & 14 & 204-212 \\
\hline FR-Lq2 & Laqueuille & Allard et al. & 2007 & Agric. Ecosys. Environ. & 121 & $47-58$ \\
\hline IE-Ca2 & Carlow & Abdalla et al. & 2009 & Geoderma & 151 & $327-337$ \\
\hline IE-Dri & Dripsey & Byrne et al. & 2005 & Agric. Forest Meteorol. & 135 & $82-92$ \\
\hline NL-Ca1 & Cabauw & Jacobs et al. & 2007 & Biogeosciences & 4 & $803-816$ \\
\hline UK-EBu & Easter Bush & Milford et al. & 2001 & Water Air Soil Pollution Focus & 1 & $167-176$ \\
\hline BE-Lon & Lonzee & Moureaux et al. & 2006 & Agric. Forest Meteorol. & 139 & $25-39$ \\
\hline DE-Geb & Gebesee & Anthoni et al. & 2004 & Agric. Forest Meteorol. & 121 & $55-67$ \\
\hline DE-Kli & Klingenberg & Tittebrand et al. & 2009 & Theor. Appl. Climatol. & 98 & $171-186$ \\
\hline DK-Ris & Risbyholm & Houborg and Soegaard & 2004 & Remote Sensing Environ. & 93 & $150-167$ \\
\hline FR-Gri & Grignon & Lamaud et al. & 2009 & Agric. Forest Meteorol. & 149 & $1385-1396$ \\
\hline IT-BCi & Borgo Cioffi & Vitale et al. & 2009 & Acta Physiol. Plant. & 31 & $331-341$ \\
\hline IT-Cas & Castellaro & Rossini et al. & 2010 & Agric. Forest Meteorol. & 150 & $1283-1296$ \\
\hline UA-Pet & Petrodolinskoye & Medinets et al. & 2009 & $\begin{array}{l}\text { Ecology of the cities and recreation zones, } \\
\text { ISBN 978-966-8885-28-0 (in russian) }\end{array}$ & & $103-107$ \\
\hline UK-ESa & East Saltoun & http://www.geos.ed.ac.uk/ & search $/ \mathrm{n}$ & icromet/Current/esaltoun/ & & \\
\hline
\end{tabular}

2 
1 Table A2. Summary of input data used in model base runs and tested for sensitivity in 2 alternative runs.

\begin{tabular}{|c|c|c|c|c|c|}
\hline Model runs & LAI & $\boldsymbol{h}_{\mathrm{c}}$ & Temperature & $\begin{array}{l}\text { Relative } \\
\text { humidity }\end{array}$ & $\begin{array}{c}\text { Stability } \\
\text { corrections }\end{array}$ \\
\hline \multicolumn{6}{|l|}{ Base Runs } \\
\hline ModLAI / MeasHc & Model default & Measured & Ambient & Ambient & Yes \\
\hline \multicolumn{6}{|l|}{ Alternative Runs } \\
\hline ModLAI / ModHc & Model default & Model default & Ambient & Ambient & Yes \\
\hline MeasLAI / MeasHc & Measured & Measured & Ambient & Ambient & Yes \\
\hline Surface Potentials & Model default & Measured & $z_{0}$ & $z_{0}$ & Yes \\
\hline No stability correction (CBED) & Model default & Measured & Ambient & Ambient & No \\
\hline
\end{tabular}

3 


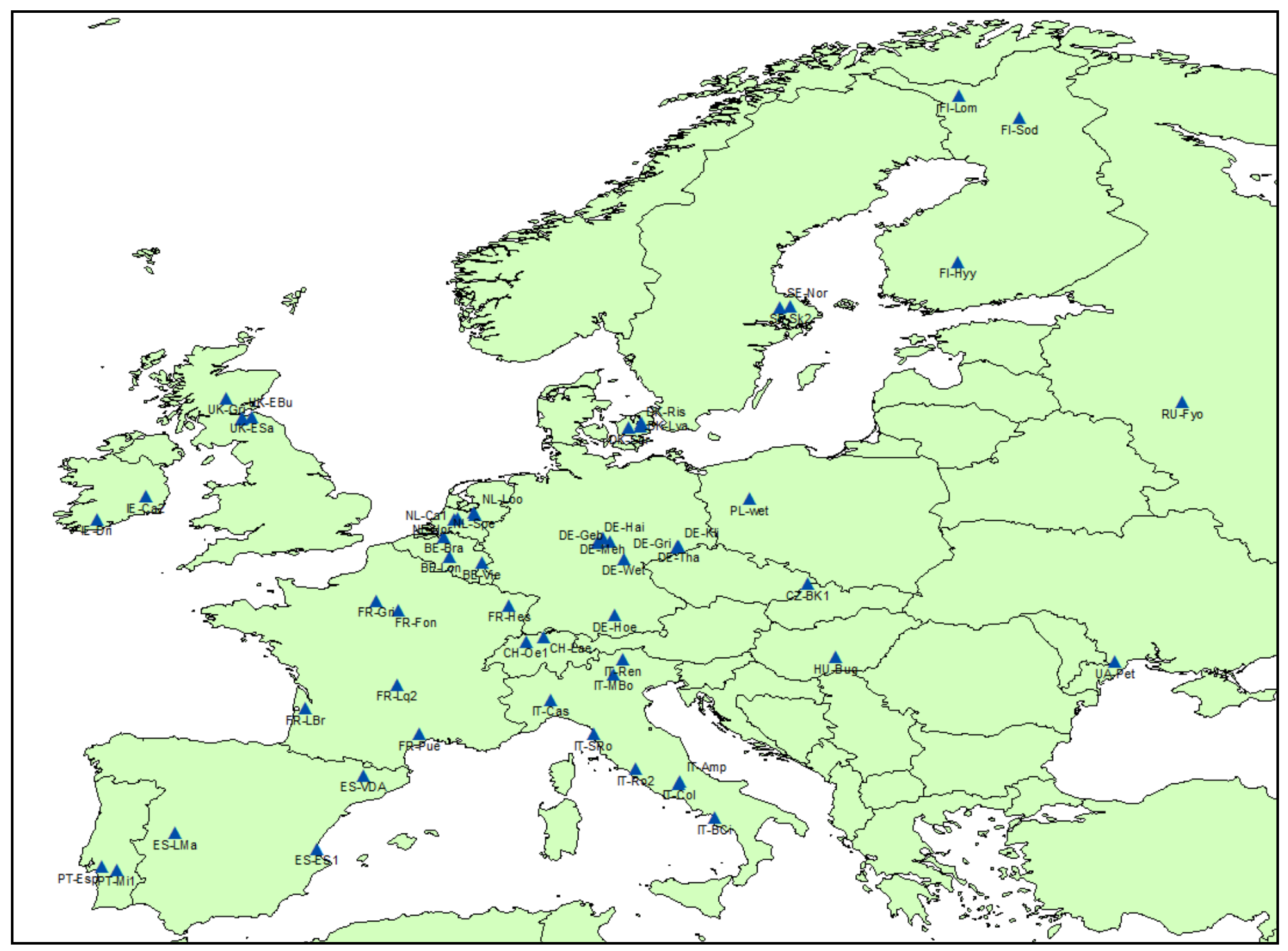



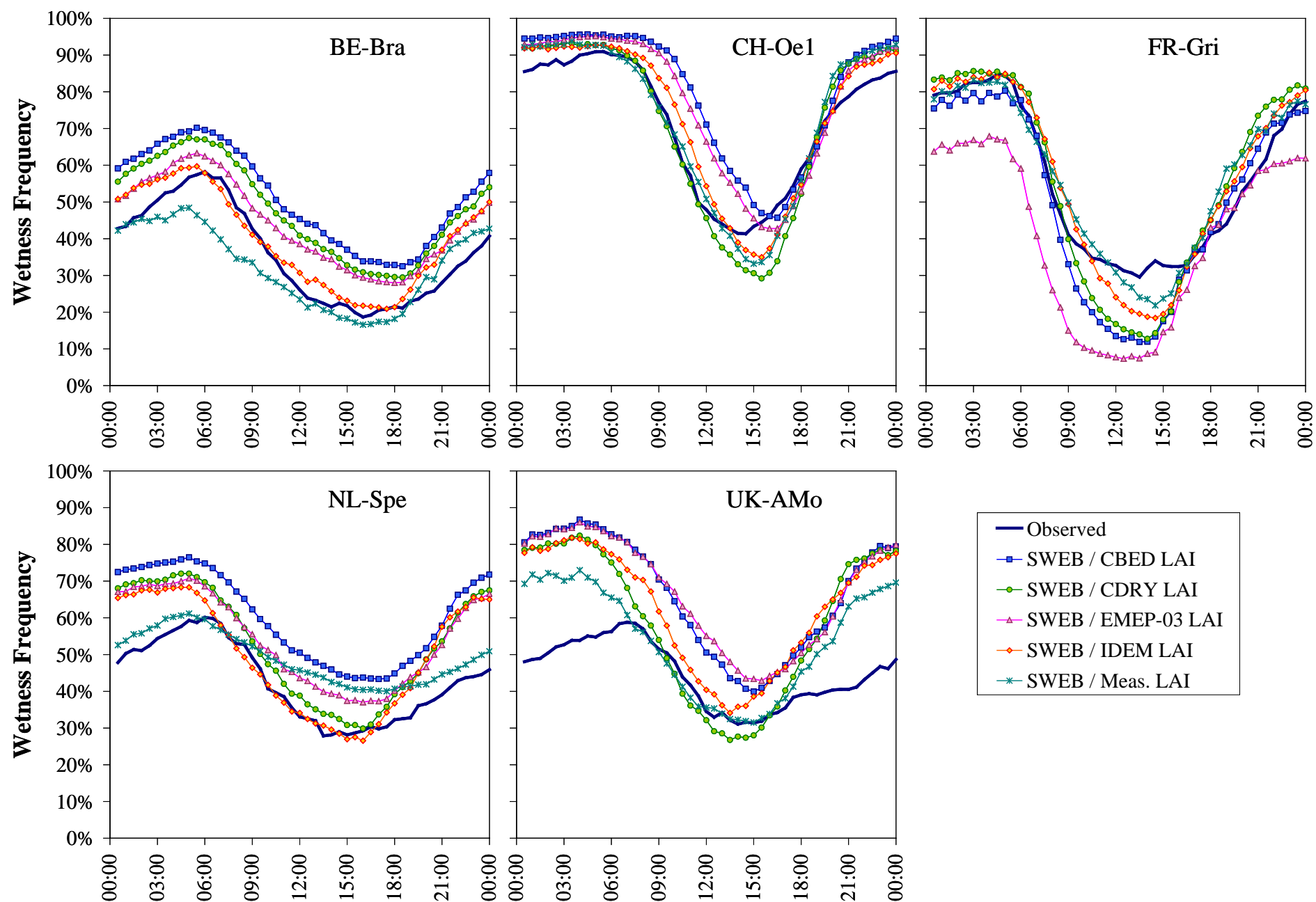

$$
\begin{aligned}
& \text { - Observed } \\
& \rightarrow \text { SWEB / CBED LAI } \\
& \rightarrow \text { SWEB / CDRY LAI } \\
& \rightarrow \text { SWEB / EMEP-03 LAI } \\
& \rightarrow \text { SWEB / IDEM LAI } \\
& * \text { SWEB / Meas. LAI }
\end{aligned}
$$

Figure A2. Comparison of observed and modelled annual diurnal cycles of canopy wetness frequency at five sites of the inferential network. Modelled values were obtained by running the surface wetness energy balance model (SWEB, Magarey et al., 2006), using as input either the model default LAI values for each of CBED, CDRY, EMEP-03 and IDEM, or using the measured LAI. 


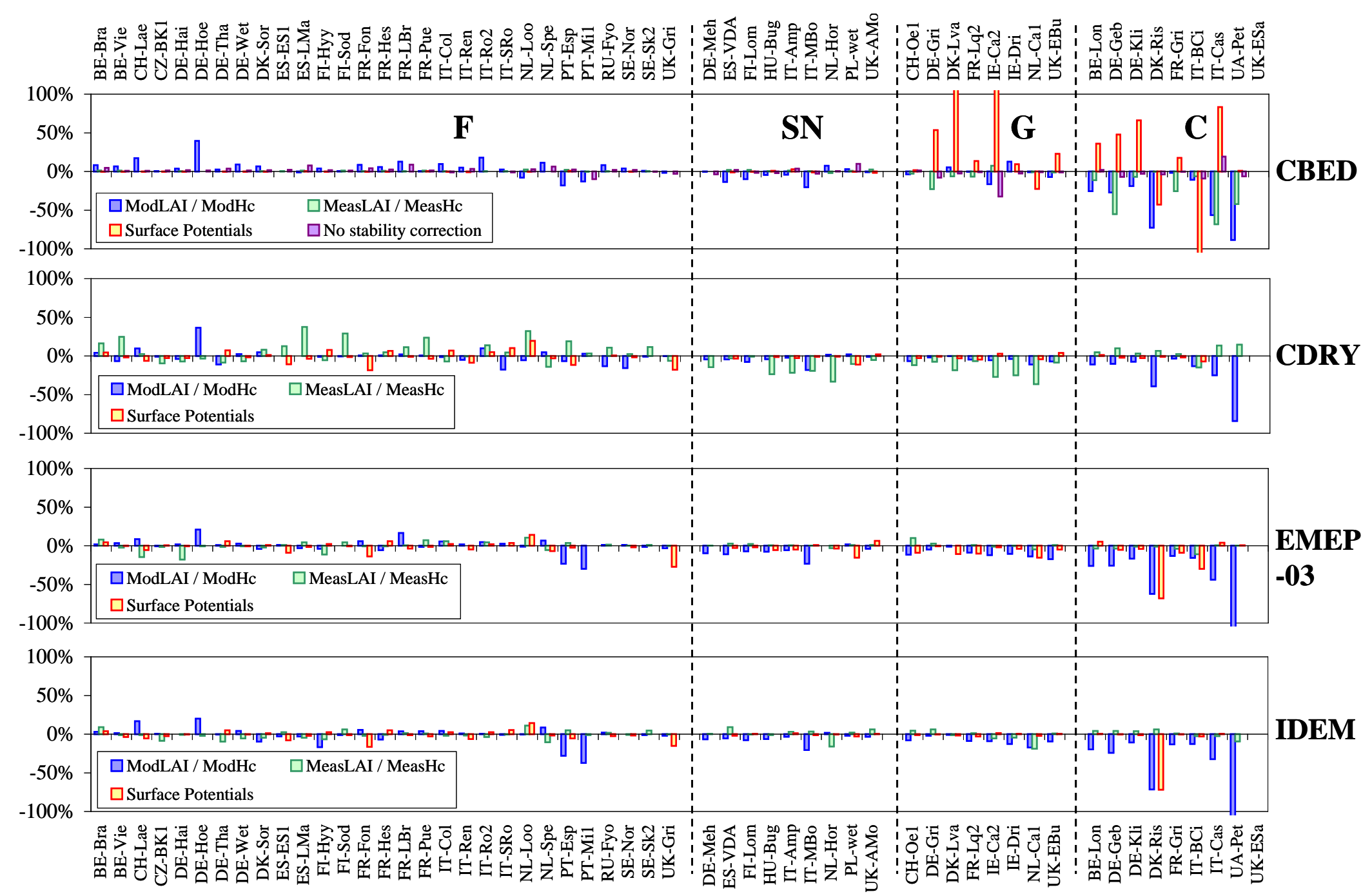

Figure A3. Sensitivity of modelled annual $\mathrm{N}_{\mathrm{r}}$ dry deposition fluxes to the choice of input data for LAI, $h_{\mathrm{c}}$ (measured vs model default), to the use of temperature and relative humidity at the surface $\left(d+z_{0}{ }^{\prime}\right)$ rather than ambient, and to the non-implementation of stability corrections (CBED only). The percentage differences are expressed relative to the model base runs as detailed in Table A2, with a negative number indicating larger dry deposition (or smaller emission), and a positive number indicating smaller dry deposition (larger emission). 